\title{
Phenotypic Diversity of Clarias gariepinus (Burchell, 1822) from Benue River and a Tributary in North East Nigeria.
}

\author{
Mamndeyati Ndekimbe Uruku 1, ${ }^{*}$, Innocent Agbo Adikwu 2, Oyediran Olusegun Oyebola ${ }^{3}$, and Timothy E. \\ Uchendu ${ }^{3}$ \\ ${ }_{1}^{1}$ Department of Fisheries and Aquaculture, Federal University Wukari P.M.B 1020, Taraba State. Nigeria. \\ ${ }^{2}$ Department of Biological Sciences. Benue State University. P.M.B 102119 Makurdi, Nigeria. \\ ${ }^{3}$ Department of Aquaculture and Fisheries Management, University of Ibadan, Nigeria.
}

Magna Scientia Advanced Biology and Pharmacy, 2021, 02(01), 009-018

Publication history: Received on 03 February 2021; revised on 09 March 2021; accepted on 11 March 2021

Article DOI: https://doi.org/10.30574/msabp.2021.2.1.0009

\begin{abstract}
Phenotypic Variability of Sampled Clarias gariepinus (Burchell, 1822) Population were assessed. 30 matured samples of Clarias gariepinus of different sizes were bought from artisanal fisherfolks using various fishing gears, morphometric and meristic attributes and other adaptive traits were characterized. Phenotypic heterogeneity (Coefficient of Variability $>10 \%$ ) and multiple modes in Meristic and morphometric Values were assessed to imply plasticity and taxonomic complications respectively. Twenty morphometric and nine meristic attributes were measured in all the collected individuals and measured to the nearest $0.01 \mathrm{~cm}$, using Vernier calipers. The mean value of meristic attributes varied from $6.20 \pm 0.93$ in PELFR-R to $71.40 \pm 5.64$ in DFR. Coefficient of variability of the population varied from 7.89 in DFR to 54.02 in PESES-L. Heterogeneity occurred in 77.8\% of meristic attributes except DFR and CFR. Multiple modal was recorded in PESES-L, while the mean value of the morphometric attributes varied from 5.20 \pm 0.82 in $0 P D$ to $64.52 \pm 5.00$ in DFL. Coefficient of variability of the population varied from 7.76 in DFL to 18.07 in CFW. Heterogeneity occurred in $82.4 \%$ of morphometric attributes. Five components accounted for $78.65 \%$ of the total variation using Principal Component Analysis on morphometric attributes. Two of the extracted components had CV > 10 (41.70\%, and $15.02 \%)$. However, the scree plot shows the slope of the variation to favors the five component with Eigenvalue greater than one. The studied C. gariepinus population was characterized by heterogeneity of phenotypic values and the population can be taxonomically discriminated by meristic and morpho types.
\end{abstract}

Key words: Phenotypic; Morphometric; Meristic Count; Variability and Heterogeneity

\section{Introduction}

Clarias gariepinus is a freshwater catfish characterized by their ability to make use of atmospheric air and remain on the land for several hundred meters with the help of their pectoral spines [1]. They are exposed to many physical and chemical changes, ranging from human activities, temperature, and salinity changes through threatened ecosystems. Catfishes are the most diverse in the tropical South American, Africa and Asia. Owing to the fact that these organisms are restricted to the bottom of the water by lying on the mud which forms substantial part of their diet, they are commonly referred to as mud fishes [2]. Catfishes are frequently exploited by fishermen and produced in farms. Essential source of proteins from animal origin, they have gained a major economic importance [3]. Catfish is a choice food species in Nigeria. They command high demand from Aquaculturists. [4] reported that C. gariepinus has high growth rate at high stocking densities most especially, under culture condition, high fecundity rate, resistance to diseases, ability to tolerate a wide range of environmental extremes.

\footnotetext{
${ }^{*}$ Corresponding author: Mamndeyati Ndekimbe Uruku

Department of Fisheries and Aquaculture, Federal University Wukari P.M.B 1020, Taraba State. Nigeria. 
The study of differences and variability in morphometric and meristic characters of fish stocks are important in phylogenetics and this also helps in providing information for subsequent studies on the genetic improvement of stocks. Morphometric and meristic characters in fish species have been commonly used to identify fish stocks [5] and as such, these characters remain the simplest and most direct way among methods of species identification. According to the reported work of [6], analysis of phenotypic differences in morphometric characters or meristic counts is the method most commonly used to delineate stocks of fish. According to [7] this is often being used in discrimination and classification studies by statistical techniques but despite the advent of techniques which directly considers the biochemical or molecular genetic variation, these conventional methods still play vital functions in stock identification even to date [8].

Traditional methods for morphological identification are based on principal component analysis and discriminant function analysis of linear measurements [9]. Discriminant function analysis of morphological data can be used to separate two or more groups of fish individuals into multivariate spaces. However, many authors have elucidated the fact that the result from the traditional morphological measurement is sometimes contradictory and ambiguous [10]. Geometric morphometric on the other hand is a landmark-based technique and considered the most rigorous morphometric technique ever [11]. It is capable of processing morphometric data from digital images with landmark points quickly and with high precision [12]. The integration of geometric morphometric data with other analytic tools such as biochemical, geographical, molecular and morphological parameters could better describe phylogenetic relationships among fishes and shed light to many ambiguous taxonomic ranks [13].

Levels of phenotypic variation can influence rates of evolution and bias evolutionary trajectories [14]. Among vertebrates, phenotypic plasticity is considered to be greatest in fish, which have relatively higher within-population coefficients of variation of phenotypes. Studies on phenotypic variability would show trends of adaptation and divergence. This morphological divergence can sometimes be large enough, that even small population shows presence of canonical taxonomic groups.

Therefore, for improved management, morphological variation and discriminate factors for morphological divergence within the $C$. gariepinus population, in response to the environment the Benue River and it tributary were studied.

\section{Material and methods}

\subsection{Sampled Site}

The sample were collected from River Benue and Donga, River Benue which lies between latitude $8^{\circ} 10^{\prime} 58.3^{\prime \prime} \mathrm{N}$ and longitude 9044'42.32"E in DMS (Degrees Minutes Seconds) or 8.18122 and 9.74431 (in decimal degrees) while Donga River which lies between latitude $7^{\circ} 43^{\prime} 00^{\prime \prime} \mathrm{N}$ and longitude $10^{\circ} 03^{\prime} 00^{\prime \prime} \mathrm{E}$. It has an area of $3,121 \mathrm{~km}^{2}$. The River exists year round, the water volume fluctuates with seasons. The river overflows its bank during the rainy season (MayOctober) but decreases drastically in volume leaving tiny island in the middle of the River during the dry season (November-April) figure 1. The river contains several species of fish which are of economic importance to the people of Taraba State and Nigeria at large.

\subsection{Sample Collection Procedure}

Specimens of $C$. gariepinus were collected from artisanal fishermen at landing sites during a year bimonthly sampling covering wet and dry seasons. Collections were carried out with caution, in order to protect mix-up of catches from sources outside the catchment. Collected fish samples were preliminarily identified at the landing site using taxonomic keys [15] and transported to kazuh integrated farm Gindin waya wukari, Taraba state Nigeria. 


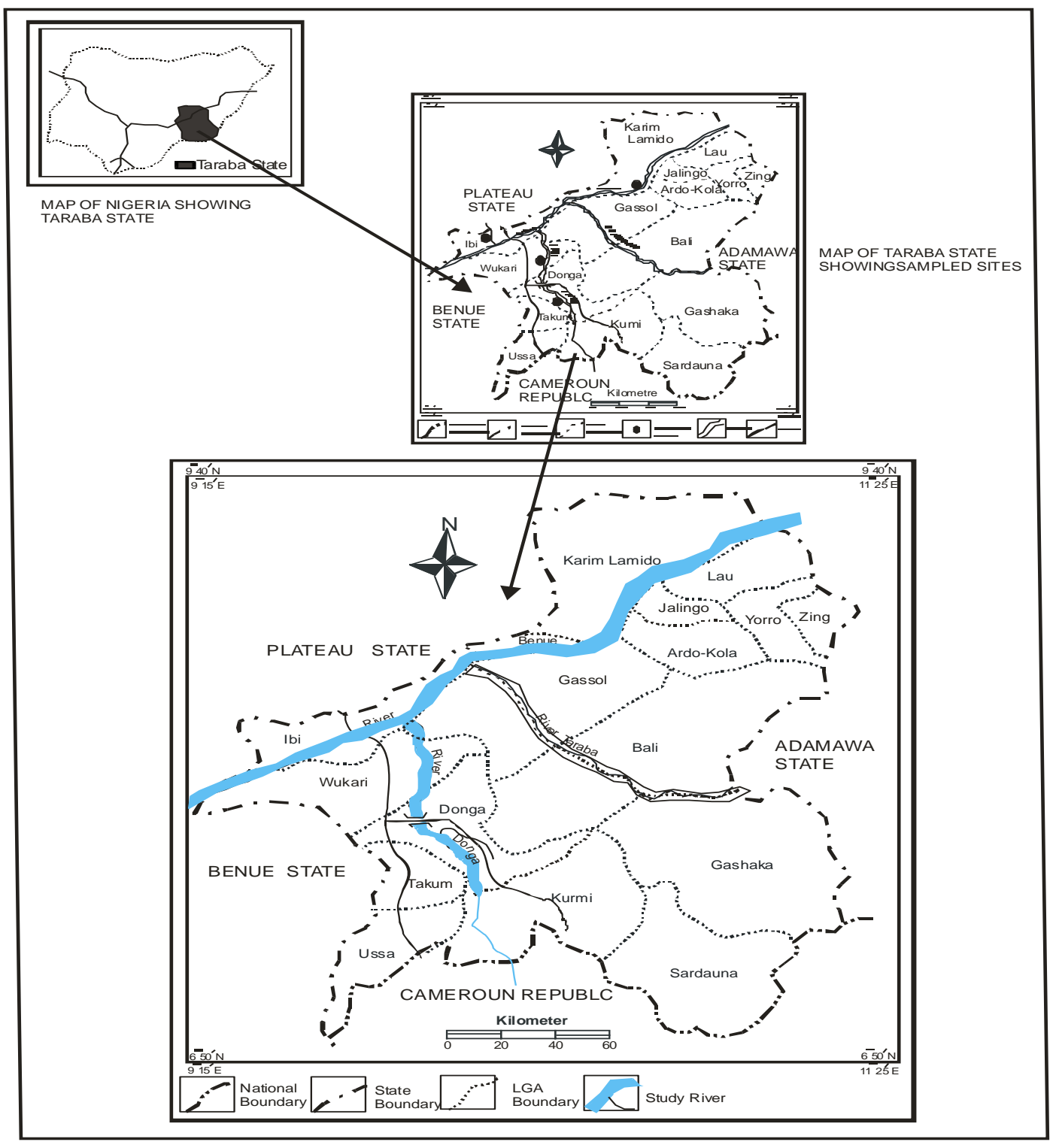

Figure 1 Map showing locations of sampling site and Rivers

\subsection{Data collection for determination of phenotypic values}

Twenty morphometric and nine meristic attributes were characterized. Data were collected from 30 individuals, being the entire population size after samples were screened. Measurements were taken from the left and right sides of paired fins of each fish sample. Morphometric measurements were taken in all the collected individuals and measured to the nearest $0.01 \mathrm{~cm}$, using Vernier calipers. All length (morphometric) measurements were taken between identical points along the anterior to the posterior axis of the fish, whereas body depths were taken perpendicularly between the identified points taken at the base of the 1st dorsal ray and at caudal peduncle (BD MAX and BDMIN, respectively). However, caudal fin width (CFW) was taken as the point of greatest perpendicular length from dorsal position of caudal fin to its ventral position. The 20 morphometric traits were measured. Landmarks showing the measured traits are presented in Figure 2. 


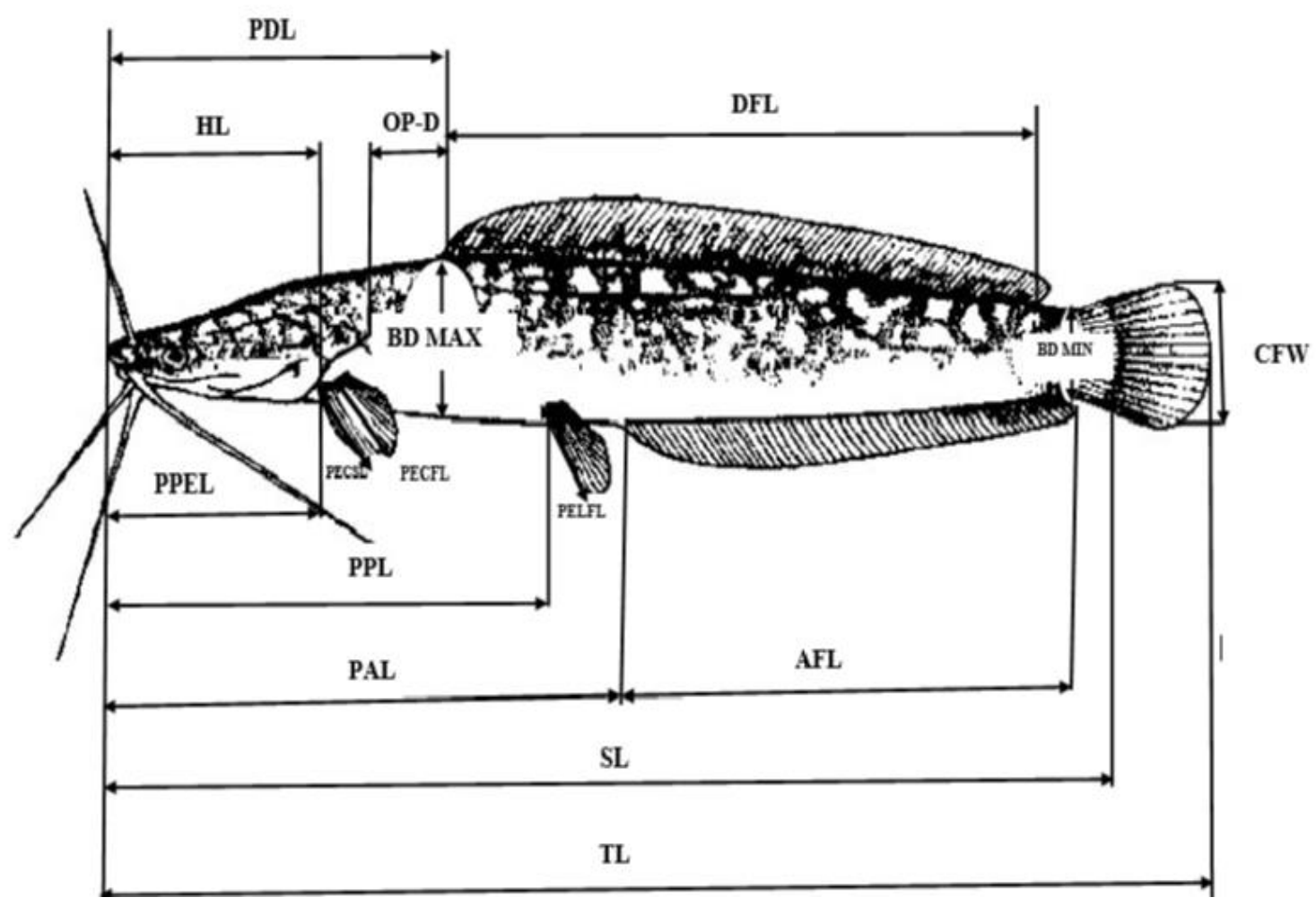

Figure 2 Landmarks showing the measured traits

The measured morphometric traits were Total length (TL), Standard length (SL), Head length (HL), Maximum body depth (BD-MAX), Minimum body depth (BD-MIN), Pectoral fin length of left side fin (PECFL-L), Pectoral fin length of right side fin (PECFL-R), Pectoral spine length of left side fin (PECSL-L), Pectoral spine length of right side fin (PECSLR), Dorsal fin length (DFL), Pelvic fin length of left side fin (PELFL-L), Pelvic fin length of right side fin (PELFL-R), Anal fin length (AFL), Caudal fin width (CFW), Pre- pectoral (PPEL), Pre pelvic (PPL), Pre-Dorsal (PDL), Pre Anal (PAL), Distance from dorsal fin to the occipital process (OPD).

The measured Nine (9) meristic attributes were Pectoral fin rays count on left side (PECFR-L), Pectoral fin ray count on the right side (PECFR-R), Possession of anteriorly serrated spine on the left side (PESES-L), Possession of anteriorly serrated spine on the right side (PESES-R), Pelvic fin rays counts on left side (PELFR-L), Pelvic fin rays counts on right side (PELFR-R), Dorsal fin rays counts (DFR), Anal fin rays counts (AFR) and Caudal fin rays counts (CFR). Each meristic attribute was counted and the number obtained was taken as their phenotypic value. However, PESES was observed in the binary form, in which presence of serration at anterior position of pectoral spine was taken as 1 , while absence was taken as zero (0). Measurements were taken by the same person to maximize consistency [6]. Meristic counts were repeated on the same specimens using hand-held magnifying lens to ensure accuracy.

\subsection{Data Processing}

Morphometric and meristic data were separately processed for analysis. These types of variables are different (morphometric are continuous and can be susceptible to environmental factors while meristics are discrete and are fixed early during development. Data on each of the morphometric attributes were processed for phenotypic value determined as morphometric value divided by standard length, multiplied by 100 percent. This is a preferred method for removing size variation characters among individuals as observed by [6]. Standard Length was preferred because its values were consistent compared to total length. The consistency of standard length has also been observed by [6, 16]. Meristic characters are independent of size of the fish and do not change during growth [17]. Therefore, raw meristic data were taken as phenotypic values and used for analysis. The mean and respective standard deviation of each of the attributes (morphometric and meristic traits) was used to derive Coefficient of Variation (CV), expressed as standard deviation divided by mean phenotypic value, multiply by 100 percent. 


\subsection{Determination of Phenotypic Variability and Trend of adaptation in Populations' Phenotypic Data}

Data on phenotypic value and Coefficient of Variation (CV) of each of the phenotypes were used as tools in assessing within-population variation, trend of adaptation and discriminant factors. The CV of each phenotype was taken as indices of flexibility or plasticity of the character. Heterogeneity of each phenotype was taken at CV> 10\%. Phenotypic plasticity was taken as indices of adaptability of the attributes. Percentage of number of the phenotypes that showed heterogeneity was documented as indices of phenotypic plasticity of the population in the catchment. For each phenotype, $\mathrm{CV}$, multiple modal values and difference between values from left and right sides of paired fins were assessed and compared. Attributes having the highest $\mathrm{CV}$, differences in values from left and right phenotypes (paired fins) and multiple modes were considered as most varied/flexible adaptive traits of the species in the environment.

\subsection{Assessment of Sources of Heterogeneity and taxonomic complications in Phenotypes' Data}

Heterogeneity of phenotypes was taken as indicative of plasticity and or taxonomic complication in the population, hence, the need to delineate the population's phenotype by potential responsible factor(s). Presence of heterogeneity in values of morphometric traits alongside multiple modes in important taxonomic traits (dorsal fin ray count- DR and Anal fin ray count- AFR) were taken as indicative of taxonomic complications in the population following [6, 18]. The DR and AFR were taken as important taxonomic factors, being the main identification keys for the species [15]. To understand the pattern of distribution of fish sample, their occurrence in similar ecological conditions Principal Component Analysis was done. For this, the data regarding the number of individual's data was put to software analyses.

\subsection{Statistical Analysis}

Univariate statistics such as minimum, maximum, mean, mode and standard deviation was used to describe phenotypes. One-way analysis of variance (ANOVA), followed by Turkey multiple comparison test for unequal sample sizes [19] was used to establish significant difference in size. Significant differences were taken at $\mathrm{p}<0.05$. Within group Principal Component Analysis were established to test for adequacy of the variations in morphometric attributes. All analyses were conducted using computer software (SPSS 15.0 Windows Evaluation).

\section{Results}

Results on phenotypic structure of the studied C. gariepinus population and analyses of contributory factors responsible for heterogeneity are presented in this section. Descriptive statistics on phenotypic values and coefficient of variation in meristic characteristics of the studied C. gariepinus populations are presented in Table 1 . The mean value of meristic

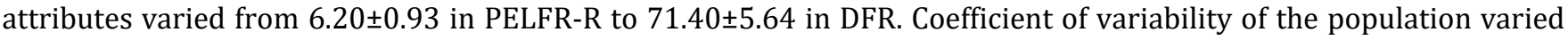
from 7.89 in DFR to 54.02 in PESES-L. A total of $77.8 \%$ of meristic attributes were heterogeneous (CV $>10 \%)$. All the meristic attributes except DFR and CFR have heterogeneous status (CV=7.89\% and 9.59\% respectively). Multiple modal was recorded in only PESES-L.

Table 1 Phenotypic Values and Coefficient of Variation (CV) of Meristic Attributes of the Studied Sample Population $(\mathrm{N}=30)$

\begin{tabular}{|l|l|l|l|l|l|}
\hline Phenotype & Minimum & Maximum & Mean \pm SD & CV (\%) & Mode \\
\hline PECFR-L & 3 & 10 & $8.33 \pm 1.30$ & 15.55 & 8 \\
\hline PECFR-R & 6 & 10 & $8.43 \pm 0.86$ & 10.18 & 8 \\
\hline PESES-L & 0 & 21 & $11.00 \pm 5.94$ & 54.02 & $8^{\text {a }}$ \\
\hline PESES-R & 0 & 24 & $11.17 \pm 5.87$ & 52.54 & 10 \\
\hline PELFR-L & 6 & 10 & $6.23 \pm 0.90$ & 14.40 & 6 \\
\hline PELFR-R & 4 & 10 & $6.20 \pm 0.92$ & 14.92 & 6 \\
\hline DFR & 53 & 80 & $71.40 \pm 5.64$ & 7.89 & 69 \\
\hline AFR & 34 & 63 & $52.33 \pm 5.42$ & 10.35 & 54 \\
\hline CFR & 14 & 21 & $17.73 \pm 1.70$ & 9.59 & 18 \\
\hline
\end{tabular}


a: Multiple mode, PECFR-L: Pectoral fin rays count on left side, PECFR-R: Pectoral fin ray count on the right side, PESESL: Possession of anteriorly serrated spine on the left side, PESES-R: Possession of anteriorly serrated spine on the right side, PELFR-L: Pelvic fin rays count on left side, PELFR-R: Pelvic fin rays count on right side, DFR: Dorsal fin rays count, AFR: Anal fin rays count, CFR: Caudal fin rays count.

The mean value of the morphometric attributes (Table 2) varied from 5.20 \pm 0.82 in OPD to 64.52 \pm 5.00 in DFL. Coefficient of variability of the population varied from 7.76 in DFL to 18.07 in CFW. A total of $82.4 \%$ of morphometric attributes were heterogeneous ( $\mathrm{CV}>10 \%$ ). Meanwhile, multiple modes were recorded in $58.8 \%$ of the attributes.

Table 2 Phenotypic values (as \%SL.) and Coefficient of Variation (CV) of Morphometric Attributes of the Studied Sample Population $(\mathrm{N}=30)$

\begin{tabular}{|l|l|l|l|l|l|}
\hline Phenotype & Minimum & Maximum & Mean \pm SD & CV (\%) & Mode \\
\hline HL & 15.00 & 41.00 & $28.31 \pm 4.11$ & 14.51 & $25.00^{\mathrm{a}}$ \\
\hline BD-MAX & 10.00 & 17.00 & $12.32 \pm 1.57$ & 12.71 & $10.00^{\mathrm{a}}$ \\
\hline BD-MIN & 6.00 & 15.00 & $8.26 \pm 1.65$ & 19.99 & $8.00^{\mathrm{a}}$ \\
\hline PECFL-L & 9.00 & 15.00 & $11.57 \pm 1.71$ & 14.79 & 10.00 \\
\hline PECFL-R & 9.00 & 15.00 & $11.57 \pm 1.63$ & 14.10 & $10.00^{\mathrm{a}}$ \\
\hline PECSL-L & 6.00 & 12.00 & $8.44 \pm 1.42$ & 16.78 & $7.00^{\mathrm{a}}$ \\
\hline PECSL-R & 7.00 & 12.00 & $8.52 \pm 1.24$ & 14.49 & $8.00^{\mathrm{a}}$ \\
\hline DFL & 57.00 & 81.00 & $64.52 \pm 5.00$ & 7.76 & $57.00^{\mathrm{a}}$ \\
\hline PELFL-L & 8.00 & 12.00 & $9.55 \pm 1.16$ & 12.18 & 9.00 \\
\hline PELFL-R & 8.00 & 13.00 & $9.60 \pm 1.05$ & 10.94 & 10 \\
\hline AFL & 39.00 & 56.00 & $44.39 \pm 3.91$ & 8.81 & 46 \\
\hline CFW & 7.00 & 14.00 & $10.53 \pm 1.90$ & 18.07 & 10.00 \\
\hline PPEL & 19.00 & 31.00 & $22.10 \pm 2.56$ & 11.57 & $22.00^{\mathrm{a}}$ \\
\hline PPL & 39.00 & 60.00 & $46.65 \pm 4.75$ & 10.18 & 50.00 \\
\hline PDL & 21.00 & 47.00 & $36.54 \pm 5.23$ & 14.30 & 40.00 \\
\hline PAL & 41.00 & 65.00 & $55.56 \pm 4.94$ & 8.89 & $56.00^{\mathrm{a}}$ \\
\hline OPD & 4.00 & 8.00 & $5.20 \pm 0.82$ & 15.69 & $4.00^{\mathrm{a}}$ \\
\hline & & & $\mathrm{a}=$ Multiple modes & & \\
\hline
\end{tabular}

Head length (HL), Maximum body depth (BD-MAX), Minimum body depth (BD-MIN), Pectoral fin length of left side fin (PECFL-L), Pectoral fin length of right side fin (PECFL-R), Pectoral spine length of left side fin (PECSL-L), Pectoral spine length of right side fin (PECSL-R), Dorsal fin length (DFL), Pelvic fin length of left side fin (PELFL-L), Pelvic fin length of right side fin (PELFL-R), Anal fin length (AFL), Caudal fin width (CFW), Pre- pectoral (PPEL), Pre pelvic (PPL), Pre-Dorsal (PDL), Pre Anal (PAL), Distance from dorsal fin to the occipital process (OPD).

Summary of Principal Component Analysis revealed that Five components accounted for 78.65\% of the total variation in the populations' morphometric data. Two of the extracted components had CV > $10(41.70 \%$, and $15.02 \%)$. These two components accounted for $56.72 \%$ of the total variation in the sample. However, the scree plot (Figure 3), shows that the slope of the variation favors the five component with Eigenvalue greater than one. Thus five components were extracted accounting for $78.65 \%$. Factor loadings for these five extracted principal components (Table 3) revealed that at \pm 0.10 high loading, PDL and PAL were negative on component 1 while BD-MAX, DFL, AFL, PPEL, PPL and OPD were positive. The CFW was negative on component 2, while TL, SL and WT were positive. On component 3, PECSL-R and PPL were negative, while BD-MIN, PECFL-L, PELFL-L and PELFL-R were positive. The PECFL-L, PECFL-R, PECSL-L, PECSL-R and WT were negative in component 4, while BD-MIN, PPEL, PAL and OPD were positive. On component 5, DFL, AFL, CFW and WT were negative, while HL, PPEL, PDL and OPD were positive. 


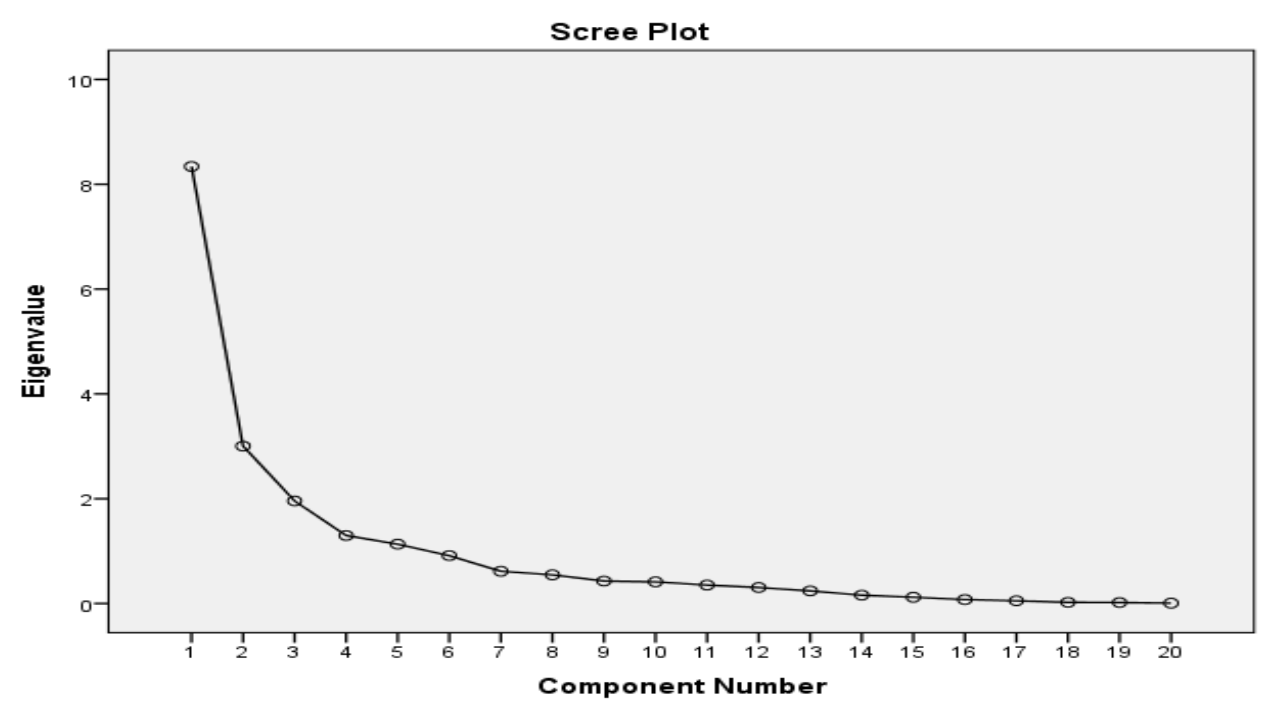

Figure 3 Scree plot of Principal Component Analysis (PCA) of the Studied Sample Population (N=30)

Table 3 Factor loadings for the first three principal components formed from the morphometric variables of the Studied Population $(\mathrm{N}=30)$

\begin{tabular}{|c|c|c|c|c|c|}
\hline \multirow[t]{2}{*}{ Variables } & \multicolumn{4}{|c|}{ Component } & \multirow[b]{2}{*}{5} \\
\hline & 1 & 2 & 3 & 4 & \\
\hline $\mathrm{TL}$ & 0.010 & 0.344 & 0.067 & 0.042 & 0.011 \\
\hline SL & 0.008 & 0.339 & 0.046 & 0.044 & 0.055 \\
\hline $\mathrm{HL}$ & 0.025 & -0.058 & 0.027 & -0.032 & 0.675 \\
\hline BD-MAX & 0.129 & -0.010 & -0.079 & -0.088 & 0.064 \\
\hline BD-MIN & 0.010 & 0.000 & 0.337 & 0.193 & -0.026 \\
\hline PECFL-L & -0.085 & 0.042 & 0.191 & -0.221 & 0.029 \\
\hline PECFL-R & 0.000 & -0.021 & -0.016 & -0.283 & -0.010 \\
\hline PECSL-L & -0.070 & 0.013 & -0.039 & -0.384 & 0.072 \\
\hline PECSL-R & 0.054 & -0.030 & -0.106 & -0.238 & -0.031 \\
\hline DFL & 0.171 & -0.011 & 0.032 & 0.050 & -0.121 \\
\hline PELFL-L & -0.030 & 0.028 & 0.315 & -0.006 & 0.070 \\
\hline PELFL-R & -0.017 & -0.033 & 0.219 & -0.087 & -0.003 \\
\hline AFL & 0.100 & 0.003 & 0.051 & -0.083 & -0.133 \\
\hline CFW & 0.037 & -0.156 & 0.078 & 0.034 & -0.459 \\
\hline PPEL & 0.184 & 0.005 & 0.027 & 0.109 & 0.185 \\
\hline PPL & 0.214 & 0.052 & -0.122 & 0.098 & 0.037 \\
\hline PDL & -0.164 & -0.007 & -0.033 & -0.024 & 0.114 \\
\hline PAL & -0.117 & -0.047 & 0.017 & 0.106 & 0.079 \\
\hline OPD & 0.151 & -0.086 & 0.081 & 0.150 & 0.148 \\
\hline WT & 0.010 & 0.275 & -0.071 & -0.126 & -0.255 \\
\hline
\end{tabular}




\section{Discussion}

The results of the present study indicate an agreement with $[6,20]$ who observed that some morphological characters of fish were useful in generating heterogeneity in morphology. The morphometric variability among the fish samples in this study was mainly due to the variation of characters related to fins, and body characteristic. It also signifies coherence with the hypothesis that organisms inhabiting an environment will have to adapt in order to survive and the trend of adaptation could be detected through morphological studies. Attributes showed different degree of variability within the studied population, thus agreeing with the observation that phenotypes variability could vary within a single population [18]. The observed differences in variability in phenotypic values of the studied attributes could indicate plasticity of phenotypic traits of the population and this could be in response to variations in environmental conditions of the Rivers.

[21] reported that morphological features are adaptive; that is, they evolve and diversify owing to competition, predation, or other biotic interactions which would lead to changing structure as a result of complex interactions with other species or new environmental constraints. Therefore, pattern of variation in the haplotypes could indicate trend of morphological adaptation to the conditions of the environment. The most varied among morphometric and meristic traits of the population were the pectoral fin attributes: PELFR-L (pelvic fin rays) and PESES (possession of anteriorly serrated pectoral spine) respectively. The meristic attributes were heterogeneous (cv >10). It can be insinuated that pectoral spine attributes were under serious selective pressure and individuals of the population are showing flexibility of this attributes at different extent. Hence, the highest variability or flexibility of the pectoral spine attributes.

Trend of compromising identity within population may signal an evolving trend of adaptation which could have taxonomic implications. Meristic characters are countable structures that are fixed in embryos or larvae [5]. Characters such as number of spines and fin rays permit greater accuracy than linear measurements in the systematic populations of fishes [18]. The PESES and DR were the most important attributes with respect to variation pattern in meristic attributes. The high coefficient of variation, with mono-modal value in PESES implies that pattern of variability at this site, is a general trend in the population. Multiple modal values obtained in the PESES-L alongside heterogeneity of most morphometric traits and a meristic traits underlines need for delineating the population to morphotypes, this is necessary because, multiple modes may indicate presence of morphologic types in fish [22] especially when the affected attribute is a strong taxonomic trait. According to [15] the most vital external characteristics for identifying fish are fin ray counts, especially those of the dorsal and anal fins. [23] had observed high phenotypic differences in C. gariepinus and asserted that this may be due to presence of other taxa in the population. Hence, the subgroups can be viewed as morphs of the studied C. gariepinus population. Presence of morphs could have genetic and or environmental basis. [24] reported that morphological changes among species reflect at least, in part, the differentiated use of resources and ecological differences.

Principal Component Analysis revealed that Five components accounted for $78.65 \%$ of the total variation in the populations' morphometric data. Two of the extracted components had CV > 10 (41.70\%, and 15.02\%). These two components accounted for $56.72 \%$ of the total variation in the sample. However, the scree plot (Figure 2), shows that the slope of the variation favors the five component with Eigenvalue greater than one. These can be attributed to the amount of variability observed ranged differently between components of fish samples identified on the basis of number of species, their abundance and infrequent nature. The overall variance analyzed is indicative of well-established assemblages under the prevalent ecological conditions in the Benue river and it tributary.

This present study reveals the phenotypic diversity of $C$. gariepinus strains to be high between the population. This agrees with the reported work of [25] who reported high phenotypic plasticity of African catfish. Phenotypic plasticity is involved in forming adaptive variations and resource polymorphism [26]. Phenotypic plasticity is an environmentinduced phenotypic change that occurs within an organism's lifetime and it is likely to play an important role in the process of diversification [6]. The studied C. gariepinus population was characterized by heterogeneity of phenotypic values and the population can be taxonomically discriminated by meristic and morphological types.

\section{Conclusion}

Fish generally demonstrate greater variance in both morphological and meristic traits within populations than do any other vertebrate. The studied $C$. gariepinus population was characterized by heterogeneity of phenotypic values and the population were taxonomically discriminated by component value analysis and morpho types. 


\section{Compliance with ethical standards}

Fish used in this study were handled according to the Canadian Council on Animal Care's Guide to the Care and Use of Experimental Animals (CCAC Guide)

\section{Acknowledgments}

TETFUND Nigeria is acknowledged for providing financial support and Hon. Yakubu Agbaizu, Director Kazuh Integrated Farms for his kind support and providing enabling environment.

\section{Disclosure of conflict of interest}

Authors have declared that no competing interests.

\section{References}

[1] Teugels GG. Taxonomy, phylogeny and biogeography of catfishes (Ostariophysi, Siluroidei): an overview. Aquatic Living Resource. 1996; 9:9 - 34.

[2] Teugels GG. Preliminary results of a morphological study of five African species of the subgenus Clarias(Clarias) (Pisces; Clariidae). J. Natur. His. 1982; 16(3):439 - 464.

[3] Legendre M, Teugels GG, Cauty C, Jalabert B A. Comparative study on morphology, growth rate and reproduction of Clarias gariepinus (Burchell, 1822), Heterobranchus longifilis (Valenciennes,1840) and their reciprocal hybrids (Pisces,Clariidae). J. Fish Biol. 1992; 40:59-79.

[4] Fagbuaro 0. Aquacultural implications of Cephalic deformity inthe African Catfish, Clarias gariepinus (Burchell, 1822). J. Appl. And Envtal. Sci. 2010; 6(1):112 - 119.

[5] Turan C. Stock Identification of Mediterranean Horse Mackerel (Trachurus mediterraneus) using orphometric and meristic characters. ICES Journal of Marine Science. 2004; 61:774 - 781.

[6] Oyebola 00. Phenotypic Variability Revealed Discriminate Pectoral Spine Variants in Small Population of Clarias gariepinus (Burchell, 1822) of Hydrodynamic Environment. Nature Science. 2015; 13(3):96-108]. (ISSN: 15450740).

[7] Avsar D. Stock differentiation study of the sprat off the southern coast of the Black Sea -Fish. Res. 1994; 19:363 378.

[8] Swain DP, Foote CJ. Stocks and chameleons the use of phenotypic variation in stock identification Fish. Res. 1999; 43:113-128.

[9] Neff NA, Smith GR. Multivariate analysis of hybrid fishes. Syst. Zool. 1979; 28:176 - 196.

[10] Rincon PA. Big fish, small fish: still the same species. Lack of morphometric evidence of the existence of two sturgeon species in the Guadalquivir River. Mar. Biol.2000; 136:715 - 723.

[11] Bagherian A, Rahmani H. Morphological discrimination between two populations of shemaya, Chalcalburnus chalcoides (Actinopterygii, Cyprinidae), using a truss network. Anim. Biodiver. Conserv. 2009; $32: 1$ - 8.

[12] Costa C, Tibaldi EL, Pasqualetto L, Loy A. Morphometric comparison of thecephalic region of cultured Acipenser baerii (Brandt, 1869), Acipenser naccarii (Bonaparte, 1836) and their hybrid. J. Appl. Ichthyol. 2006; 22:8-14.

[13] Loy A, Bronzi P, Molteni S. Geometric morphometrics in the characterization of the cranial growth pattern of Adriatic sturgeon Acipenser naccarii. J. Appl. Ichthyol. 1999; 15:50 - 53.

[14] Mc-Guigan, K, Chenoweth SF, Blows MW. Phenotypic divergence along lines of genetic variance. The American Naturalist. 2005; 165:32 - 43.

[15] Holden M, Reeds W. West African fresh water fish: West African nature and book. London: Longman Publication. 1978; 61pp.

[16] Gunawickrama KBS. Morphological heterogeneity in some estuarine populations of the Catfish Arius jella (Ariidae) in Sri lanka, Cey Journal of Science (Bio Sci). 2007; 36(2):100-107.

[17] Murta AG. Morphological variation of horse mackerel (Trachurus trachurus) in the Iberian and North African Atlantic: implications for stock identification. ICES J. Mar. Sci. 2000; 57:1240-1248. 
[18] Mayr E. Principles of systematic zoology. New York: McGraw Hill Book Company. 1969; 428pp.

[19] Zar JH. Bio-statistical analysis (second edition). New Jersey; Prentice-Hall. 1984; 78pp.

[20] Tosin VO, IvanChu CK, Anuar H, Thumronk A, Sherif MS. Morphological characterization of the progenies of pure and reciprocal crosses of Pangasianodon hypophthalmus (Sauvage, 1878) and Clarias gariepinus (Burchell, 1822). Scientific Reports 2018; 8:3827.

[21] Bock W J. Biologische anatomic to ecomorphology (Proc. 3rd International Congress on Vertebrate Morphology. Netherlands Journal of Zoology. 1990; 40:254 - 277.

[22] Guiger KRRA, Reist JD, Power M, Babaluk JA. Using stable isotopes to confirm the trophic ecology of Arctic Charrmorphotypes from Lake Hazen, Nunavut, Canada. Journal of Fish Biology. 2002; 60 (2):348 - 362.

[23] Turan C, Yalcin S, Turan F, Okur E, Akyurt I. Morphometric comparisons of African catfish, Clarias gariepinus populations in Turkey. Folia Zoology 2005; 54(1-2):165-172.

[24] Santos ABI, Camilo FL, Ailbien RJ, Araujo FG. Morphological Pattern of five species (four Characiform, one Perciform) in relation to feeding habit in a tropical reservoir in South Eastern Brazil. Journal of Applied Ichthyology 2011; 27:1360 - 1364.

[25] Solomon SG, Tiamiyu LO, Annune PA, Apochi JO. Morphometric and Meristic Diversity Between Strains of Clarias gariepinus (Burchell, 1822) From Two Eco- Regions of Nigeria. Journal of Research in Forestry, Wildlife and Environment. 2016; 8 (2):114 - 122.

[26] Skulason S, Smith TB. Resource polymorphisms in vertebrates. Trends in Ecology and Evolution1995; 10(9):366 - 370. doi: 10.1016/ S01695347(00)89135-1. 